\title{
The Design and Realization of University E-voting System
}

\author{
Haibo Zhang*, Shuyuan Shang, Wenfeng Zhai, Chunyan Zhang and Ying Zhang \\ Computer Information Center, Beijing Institute of Fashion Technology, Beijing, China \\ ${ }^{*}$ Corresponding author
}

\begin{abstract}
There are many different ways to vote in university daily management process such as title appraisal, research assessment, post evaluation and so on. Due to the variety of voting methods, inconvenience of traditional paper ballots by statistic method and targeting of electronic voting system result in the coexistence of multiple voting systems and difficulty of unified management. It demands urgently develop an electronic voting system to meet the daily needs of university poll with the deepening of higher education information technology. This paper studies the demand analysis, system design, function design, scheme design, module analysis and system development of the electronic voting system studied in this paper. And an electronic voting system containing almost all kinds of electronic voting ways suitable for the management of universities developed, which supports both the use of PC computers and mobile devices (such as tablet computers, mobile phones, etc.). What's more, the voting system will automatically carry out statistical analysis and data processing of poll results.
\end{abstract}

Keywords-university; voting management; e-voting; APP

\section{REQUIREMENTS BACKGROUND}

In the daily work of colleges and universities, it is necessary to carry out a variety of selection activities. Many of that need to organize experts, judges, teachers and students to focus on the vote scene[1], such as: title evaluation, scientific research, personnel elections, job evaluation and so on. The drawbacks of the traditional paper voting in these scenes are self-evident. Especially in the counting process, the heavy workload of the submission process, cannot be real-time display of statistical results, and sometimes the need for personal presence, and so on.

These traditional voting methods cannot meet the needs of today's colleges and universities, because of the large amount of manpower, financial resources and material resources in the process of organizing others to vote, distributing ballots, collecting votes[2].

With the popularization and rapid development of campus network, the management system of each school has been improved, and gradually entered the era of scientific, informational and regularized management. With the aid of the campus network platform, we can use computer and network technology to achieve online voting function. This not only saves a lot of resources, but also can improve the efficiency of management staff. In addition, it can also reduce the errors caused by human factors, so that the selection activities to achieve an open, fair and equitable effect[2].
Therefore, using the latest information technology and means to develop a set of safe, reliable, flexible configuration, data accuracy, easy to statistics and other characteristics of the electronic voting system can effectively enhance the university's school management information level[3].

At the same time, the electronic voting system has been gradually spread in research, program collection, elections and other fields. Electronic voting as a paperless, electronic, computerized way to vote promote and simplify the voting process. Because electronic voting systems need to meet many of the characteristics of the requirements, more important is in many requirements there are many attributes are mutually contradictory, so it faces the challenge of how to protect privacy, integrity and confidentiality[4].

In addition, the popularity of mobile phones and tablet computers, and the applications of APP, Wechat technology, provides a good hardware and software support to the electronic voting system. Through mobile phones or tablet computers, teachers and students can use fragmentation time at any time to vote anywhere.

Although with the good hardware and software conditions above and the external application environment, at present there is not a fully functional electronic voting system on the market, especially for the actual situation of colleges and universities developed.

According to the actual situation of colleges and universities, this paper analyzes the demand of electronic voting system in colleges and universities and designs the overall architecture. And then use .NET and SQL Server platform for development, the system provides $\mathrm{B} / \mathrm{S}, \mathrm{C} / \mathrm{S}$ two modes of application, to achieve a variety of ways to vote, to meet the needs of colleges and universities to vote for most of the management [5].

\section{SYSTEM DESIGN}

\section{A. System Function Design}

According to the demand analysis, the university e-voting system has designed the following functional applications:

1) Real-time voting: Users can vote in real time on the spot, you can also use the fragmented time to vote, but the voting results can be aggregated and displayed in real time statistics. 
2) Real-time voting: Users can make secret ballot and secret ballot. Open polls generally do not need to log on to vote, count as a secret ballot; internal voting can be a secret ballot, you can also vote by secret ballot. The secret ballot generated accounts by the backstage, and then printed to the appropriate individuals under the random, to ensure the anonymity of the vote.

3) Vote scoring function: Users through PC computers, mobile phones, tablet PCs and other equipment, can be a direct vote or sub-vote.

4) Voting control function: System for voting objects can be controlled according to the rules of university business, meanwhile, the related personnel information and scientific research information display and control are carried out for the voting object.

5) Result Calculations: The results of the voting system, according to the competitive election, matching election, the final score, to the highest and lowest scoring, weighted scores and other means of one or more statistical and final results.

\section{B. System Performance Design}

The university e-voting system has the following performance design:

1) Easy to operate: The e-voting system using PC machines, mobile phones and other additional equipment, to achieve full automation of voting operations.

2) Friendly interface: System interface design should be beautiful, friendly to the user, the system features easy to use.

3) Powerful function: The system fully meets the needs of voting, statistical voting results are fast and simple, improve the efficiency of voting, the statistical results are more accurate.

\section{System Security Design}

1) Application server backup design: E-voting system should be used two servers, one as a web application server, one as a database server, two service applications each other back up to ensure that the system to provide uninterrupted service for the vote.

2) Design of system role privilege: The system uses the role, sub-rights settings, all users of the role of management, through different roles to manage different permissions, thus ensuring the system's information security.

3) Security log design: All user operations are recorded as system operation logs, ensuring that all operations of the system are well documented.

4) Database backup design: System backup function through the database, the data can be backed up in a timely manner after the failure can be real-time recovery.

\section{TECHNICAL SOLUTIONS}

\section{A. System overall Module}

The university e-voting system includes: system login rights management, business application management, system log management.

Voting system users are divided into five categories of accounts: no account of anonymous users, ordinary users, account anonymous users, departmental administrators, system administrators. Anonymous users without an account can vote on public voting, under normal circumstances limit IP, such as each IP can only vote on a voting item one time. Ordinary users are generally college teachers and students, log on the system can vote on their own projects can vote. Anonymous users account is generally a teacher or an expert outside the school, mainly reflects the voting anonymity. Departmental administrators are generally set up as an administrator of each department, can be built vote project, and the management of the voting department. The system administrator is the super administrator of the system. The basic structure diagram shown in Figure I.

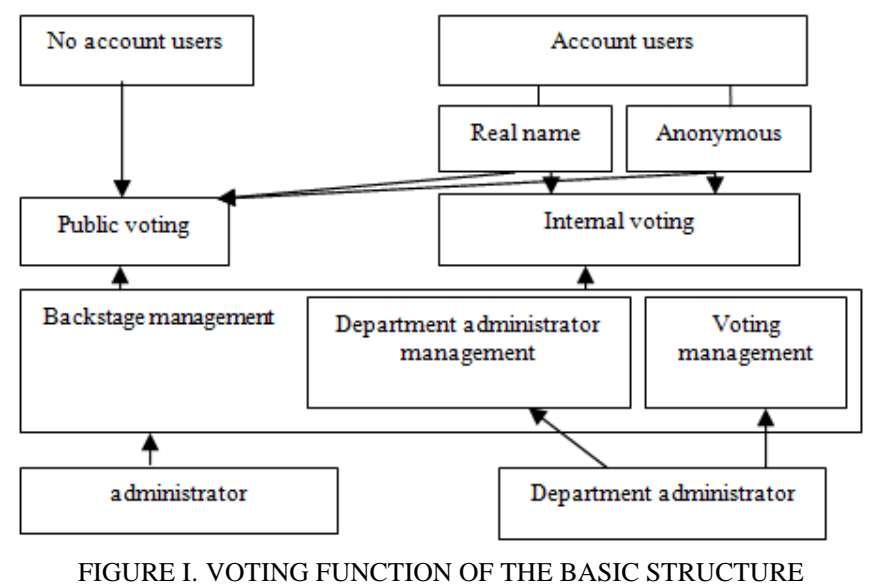

FIGURE I. VOTING FUNCTION OF THE BASIC STRUCTURE DIAGRAM

\section{B. System Overall Module}

System module design includes organization structure, user management, voting type, voting theme, voting options design, voters, counting, result show, statistical printing, user login, user voting, APP software, audit management, log management, voting results, etc. fifteen modules or subsystems. As follows table I. 
TABLE I. A BRIEF INTRODUCTION TO THE FUNCTIONAL MODULE OF E-VOTING SYSTEM IN COLLEGES AND UNIVERSITIES

\begin{tabular}{|c|c|c|}
\hline No. & $\begin{array}{l}\text { functional } \\
\text { module }\end{array}$ & Function Description \\
\hline 1 & $\begin{array}{l}\text { User } \\
\text { Manageme } \\
\text { nt }\end{array}$ & $\begin{array}{l}\text { User management module, the basic information of the } \\
\text { user is stored in the system, and users are divided into } \\
\text { groups. Including: the user's login information, the user's } \\
\text { personnel information. Need to import personnel } \\
\text { information from the personnel system to the user } \\
\text { management, including the user's age, department, job, } \\
\text { education, job titles and other information. }\end{array}$ \\
\hline 2 & $\begin{array}{l}\text { Organizati } \\
\text { onal } \\
\text { structure }\end{array}$ & $\begin{array}{l}\text { The type of organization generally includes the } \\
\text { organization itself and the administrator's new group. } \\
\text { New groups are generally created for specific polls. }\end{array}$ \\
\hline 3 & $\begin{array}{l}\text { Voting } \\
\text { theme }\end{array}$ & $\begin{array}{l}\text { Voting theme module, can be flexibly configured, } \\
\text { according to the different voting scenes to design the } \\
\text { voting theme. And to vote on the subject of voting type, } \\
\text { voting name, voting calculation method, the results show, } \\
\text { voters and other information. Such as the Design } \\
\text { Teachers' Congress, the Party Congress and so on. }\end{array}$ \\
\hline 4 & $\begin{array}{l}\text { Voting } \\
\text { type }\end{array}$ & $\begin{array}{l}\text { Voting type module, can be flexibly configured, the } \\
\text { voting type support to real-name voting, anonymous } \\
\text { voting, direct voting or voting in accordance with the } \\
\text { scores. }\end{array}$ \\
\hline 5 & $\begin{array}{l}\text { Voting } \\
\text { options } \\
\text { design }\end{array}$ & $\begin{array}{l}\text { Vote options design module, the system can be based on } \\
\text { the business scene to design vote options, through the } \\
\text { system configuration of the project, and the scoring items } \\
\text { were set scores. }\end{array}$ \\
\hline 6 & Voters & $\begin{array}{l}\text { According to different business scenarios configure the } \\
\text { voting information, the different voting topics to set a } \\
\text { different range of voters. }\end{array}$ \\
\hline 7 & Counting & $\begin{array}{l}\text { Calculates the sum of voting scores of different scoring } \\
\text { items. Including: the competitive election, matching } \\
\text { election, remove the highest and lowest score, weighted } \\
\text { scores. }\end{array}$ \\
\hline 8 & $\begin{array}{l}\text { Result } \\
\text { show }\end{array}$ & $\begin{array}{l}\text { System settings can be based on different business } \\
\text { scenarios for voting results display, including: real-time } \\
\text { display of statistical results, real-time display of charts } \\
\text { and other information, statistical information, etc. }\end{array}$ \\
\hline 9 & $\begin{array}{l}\text { Statistical } \\
\text { printing }\end{array}$ & $\begin{array}{c}\text { According to demand, print the results of statistics, } \\
\text { provide users with the final signature of the paper } \\
\text { documents. }\end{array}$ \\
\hline 10 & User login & $\begin{array}{l}\text { Internal voting requires users to vote after the system } \\
\text { login, no account of the anonymous user can vote on } \\
\text { external voting, that is to say directly as visitors to the } \\
\text { system to vote. }\end{array}$ \\
\hline 11 & $\begin{array}{l}\text { User } \\
\text { voting }\end{array}$ & $\begin{array}{l}\text { The user through the computer, tablet or mobile phone } \\
\text { voting or scoring on the topics directly. }\end{array}$ \\
\hline 12 & $\begin{array}{l}\text { APP } \\
\text { software }\end{array}$ & $\begin{array}{l}\text { Support to mobile phones and tablet PC side to use APP } \\
\text { software to vote, the operating system support to the } \\
\text { current mainstream operating system. }\end{array}$ \\
\hline 13 & $\begin{array}{l}\text { audit } \\
\text { manageme } \\
\text { nt }\end{array}$ & $\begin{array}{l}\text { Input the basic operation of the user, including: voting } \\
\text { user's login information, voting information and system } \\
\text { configuration parameters of the basic parameters. }\end{array}$ \\
\hline 14 & $\begin{array}{l}\text { Log } \\
\text { manageme } \\
\text { nt }\end{array}$ & $\begin{array}{l}\text { Record system log, including the business system log, } \\
\text { operation log, log information support to the query, only } \\
\text { the super user can delete the log operation. }\end{array}$ \\
\hline 15 & $\begin{array}{l}\text { Voting } \\
\text { results }\end{array}$ & $\begin{array}{l}\text { The voting results through statistical data or charts in the } \\
\text { form of real-time display in the voting terminal or other } \\
\text { terminal equipment. }\end{array}$ \\
\hline
\end{tabular}

\section{SYSTEM DEVELOPMENT AND IMPLEMENTATION}

According to the above analysis, trade-off the technology and demand, we decided to use.NET and MS SQL SERVER as a development and database tools to achieve the development of electronic voting system platform.

\section{A. Introduction to the Vote Function Implementation of the Foreground System}

E-voting system website platform achieves the voting notice of the information query and browse, users can make real-name, anonymous voting and voting results query.

No account of the anonymous user in the home page you can see the public vote, and vote according to the theme of each voting project.

Ordinary users or an anonymous user account, login to the user interface on the home page, as Figure 2. The user interface of the voting related to the classification, to facilitate users to quickly browse the voting information, the relevant voting content to operate. The voting columns are "All Voting", "Internal Voting", "Public Voting", "Participation Voting". The interface menu displays the voting results of the currently logged-in user and the public voting. The list updates the status of the user's operation, marks the voting that the user has participated in, and displays the date and time of the voting to prevent the user miss the vote.

\section{B. Background Voting System Management}

Background management subsystem, to achieve the news notification information release and query, voting management, statistical report output, organizational management, user management, rights management, log audit management and other functions.

1) Voting theme Settings: Voting type, release status, whether the expiration, deadline and other query conditions for voting themes. As figure III.

Click on the "theme" button to achieve the theme of the vote to add, pop up to vote for the new interface. If you set the theme of the project and set a similar theme, you can directly click on the "Select Theme" button to directly set the theme. The theme can be selected based on the type of vote (score, score, survey).

2) Voting theme release: To achieve the release of the voting theme. Select an unpublished theme to publish. The theme of the voting, the vote type, the selection type, the release status, whether the expiration date, deadline and other query conditions for voting.

3) Voting statistics: Query the voting summary information by subject name, selection type, deadline, etc.

4) Organizational Management: Enter the organization's management page can be seen in the current organization has been built "tree", click the organization name to view the organization details. Click "export", "print" can export or print the current page information. "Department Management" can 
be based on the actual situation of the unit set up multi-level departments, click on the "Department Name" view the department information, click on the department staff to see the department personnel information. Click "Add" in the popup page, fill in the blank in the new departmental information, departmental information, including departmental basic information and department heads, subordinates, information managers and other information.

5) Personnel management: Click "Department Name", the page shows the basic information of the department, click on the back of the department personnel tab, you can display the department staff information. The management of personnel can be new, delete, modify and so on.

6) Log Management: Click Log Management to open the log management page. The log records all the user's operation information, including user name, operation time, login IP, operation type (login log or log). The administrator can query the user log in this interface.

7) Authority management: Group Permission Settings: Click "Group Permission Settings" of "Rights Management" to open the group permission setting page, the group tree on the left, and the group function management page on the right.

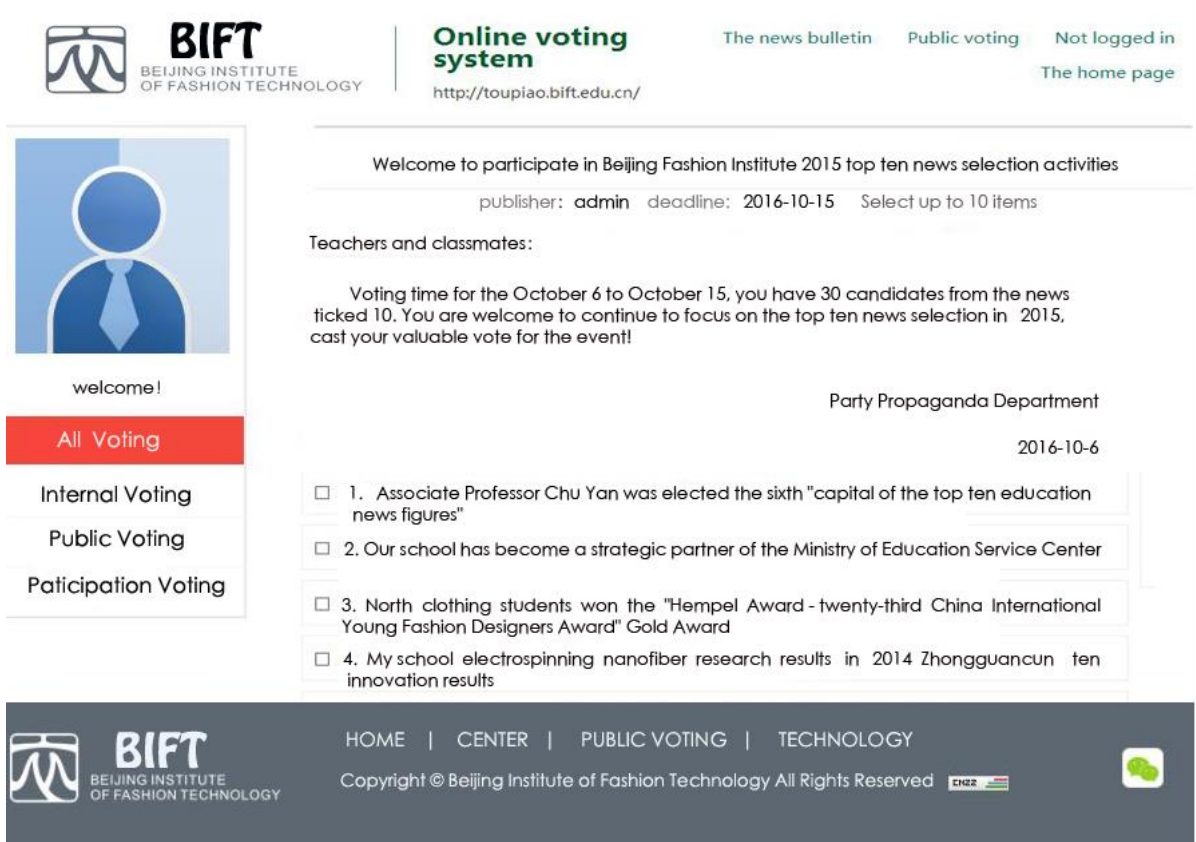

FIGURE II. THE INTERFACE THAT THE USER LOGS IN THROUGH THE PC BROWSER

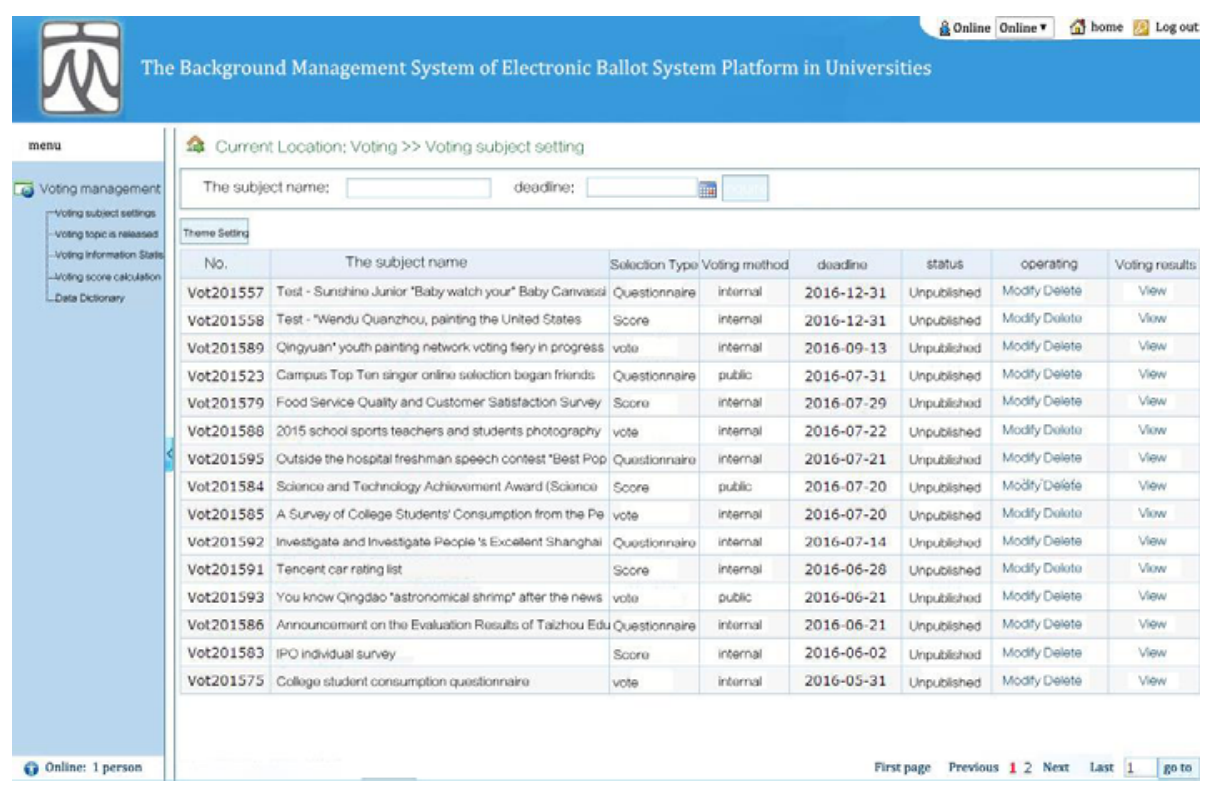

FIGURE III. BACKGROUND MANAGEMENT OF VOTING THEME SET 


\section{CONCLUSION}

According to the actual situation of the university management, the paper studies how to realize the network, automation and information of the University's voting work under the background of university informatization. On the basis of requirement analysis, system design and scheme selection, a set of e-voting system that is suitable for university management has been developed and tested, which has achieved good effect and laid a foundation for the next promotion. INTERFACE

\section{ACKNOWLEDGMENT}

The work described in this article was supported by grants from Humanities and Social Science Fund Planning Project of Chinese Education Ministry under contract No. 12YJA760089, The Science and Technology General Project of Beijing Municipal Commission of Education No.AJ2016-11, The Innovative Team and Talent Selection and Training Project of Beijing Institute of Fashion Technology. The Key Project of Education and Teaching Reform of Beijing Institute of Fashion Technology No.ZDJG-1510.

\section{REFERENCES}

[1] Wang JiaFeng. Analysis and Design of Electronic Voting Protocol in Campus Network[D].Hefei: Master 's Degree Thesis of Anhui University, 2012. (in Chinese)

[2] Sun LiHong. Design and Implementation of Online Voting System Based on Lightweight[D]. ChangChun: Master 's Degree Thesis of Jilin University,2012. (in Chinese)

[3] Huang FuRen. Research and Design of Electronic Voting[D].Hefei: Master 's Degree Thesis of china science and technology University,2010. (in Chinese)

[4] Lai XiaoJun. Analysis and design of electronic voting protocol in campus network[J]. Electronic production,2013, (6): 67,60. (in Chinese)

[5] Beijing Institute Of Fashion Technology voting website: http://toupiao.bift.edu.cn. (in Chinese) 